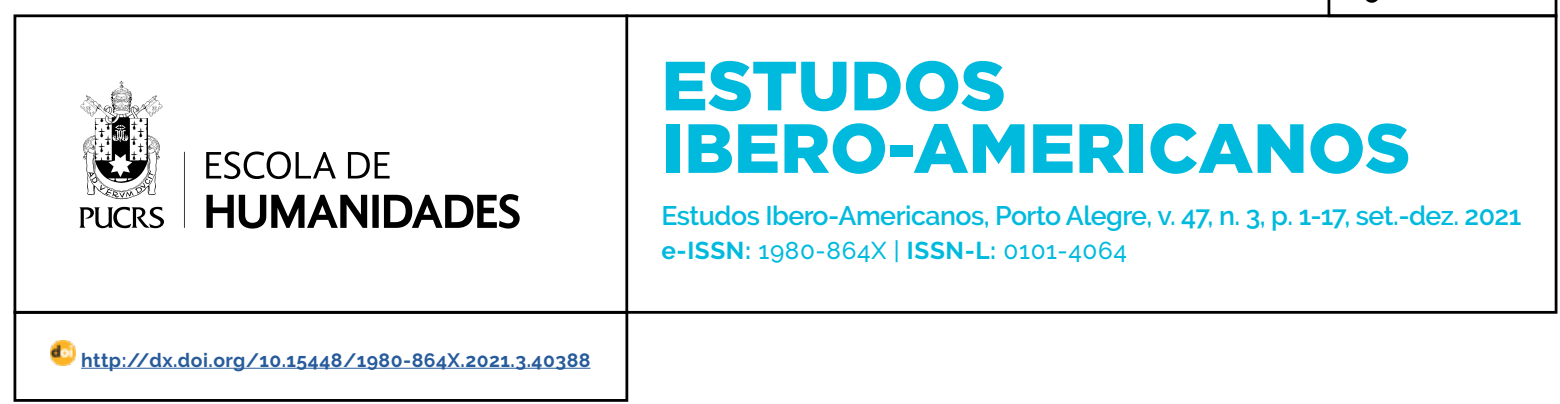

DOSSIÊ MULHERES INTELECTUAIS: PRÁTICAS CULTURAIS DE MEDIAÇÃO

\title{
Sociabilidades intelectuais, mediação cultural e recrutamento de mulheres em instituições científicas no Rio de Janeiro (1940-1960)
}

\author{
Intellectual sociabilities, cultural mediation and recruitment of women to scientific \\ institutions in Rio de Janeiro (1940-1960)
}

Sociabilidades intelectuales, la mediación cultural y el reclutamiento de las mujeres a las instituciones cientificas en Río de Janeiro (1940-1960)

\section{Daiane Silveira Rossi ${ }^{1}$ \\ orcid.org/0000-0003-3759-6285 \\ daisrossi@gmail.com}

\section{Nara Azevedo ${ }^{1}$}

orcid.org/0000-0001-9086-8134

nara.azevedo@fiocruz.br

Luiz Otávio Ferreira ${ }^{1}$ orcid.org/0000-0002-7512-7343 luiz.ferreira@fiocruz.br

Recebido em: 15 mar. 2021. Aprovado em: 7 ago. 2021 Publicado em: 17 nov. 2021.
Resumo: O artigo tem como objetivo abordar um novo padrão de sociabilidade de gênero forjado nos ambientes educativos e científicos da cidade do Rio de Janeiro nos anos 1940 e 1950. Ali se institucionalizaram práticas de mediação cultural dirigidas para a educação em ciências e a divulgação científica. Naqueles espaços surgiram oportunidades de recrutamento de estudantes e profissionais para carreiras científicas em instituições que após a Segunda Guerra Mundial passaram a oferecer oportunidades de profissionalização para mulheres. Essas questões são tratadas à luz da relação entre Newton Dias dos Santos (1916-1989). cientista mediador cultural, e Dyrce Lacombe (1932-), uma jovem estudante de quem ele foi professor e orientou para seguir a carreira cientíica.

Palavras-chave: Mediação cultural. Educação. Ciência. Mulheres.

Abstract: The article aims to address a new pattern of gendered sociability forged in the educational and scientific environments of the city of Rio de Janeiro in the 1940 s and 1950s, where cultural mediation practices directed to science education and scientific dissemination were institutionalized. In those spaces emerged opportunities for recruiting students and professionals for scientific careers in institutions that after World War II began to offer professionalization opportunities for women. These issues are addressed in light of the relationship between Newton Dias dos Santos (1916-1989) a scientist cultural mediator and Dyrce Lacombe (1932-) a young student of whom he was a teacher, and guided to follow a scientific career.

Keywords: Cultural mediation. Cultural mediation. Education. Science. Women.

Resumen: El artículo pretende abordar un nuevo patrón de sociabilidad de género forjado en los ambientes educativos y científicos de la ciudad de Río de Janeiro en las décadas de 1940 y 1950, donde se institucionalizaron prácticas de mediación cultural dirigidas a la educación científica y a la divulgación científica. En esos espacios surgieron oportunidades de reclutamiento de estudiantes y profesionales para carreras científicas en instituciones que después de la Segunda Guerra Mundial comenzaron a ofrecer oportunidades de profesionalización para las mujeres. Estas cuestiones se abordan a la luz de la relación entre Newton Dias dos Santos (1916-1989), científico mediador cultural, y Dyrce Lacombe (1932-) una joven alumna de la que fue profesor y a la que orientó para que siguiera una carrera científica

Palabras clave: Mediación cultural. Educación. Ciencia. Mujeres. 


\section{Introdução}

As políticas de educação dos anos 1920 e 1930 favoreceram a transição do perfil educacional da população feminina, que do início da República a década de 1940 evoluiu do analfabetismo à formação em nivel superior. As experiências de escolarização em diversos niveis abriram novas oportunidades profissionais para as mulheres, especialmente as que pertenciam às camadas urbanas médias e altas. Elas se direcionaram para o mundo do trabalho não doméstico, procurando ocupação nos setores de produção de bens e serviços.

Causa e efeito de mudanças operadas nos papéis sociais das mulheres naquele período, a educação imprimiu uma decisiva direção de seu ingresso no mundo acadêmico. Nesse sentido, as faculdades de filosofia, ciências e letras, que constituíram a mais importante inovação institucional do projeto de universidade no país que resultou na criação da Universidade de São Paulo (USP), em 1935; da Universidade do Distrito Federal (UDF), em 1935; e da Universidade do Brasil (UB), em 1937, foram determinantes para o acesso de mulheres ao ensino superior. Várias daquelas que ali ingressaram tiveram a oportunidade de dar sequência à trajetória acadêmica encaminhando-se aos laboratórios das instituições científicas, onde protagonizaram a invenção de um novo papel profissional. Sabendo-se que a vida acadêmica constituía então um espaço de hegemonia masculina, uma série de questões emergem a respeito de seu ingresso e da carreira que realizaram.

Neste trabalho, abordamos um aspecto relevante acerca das formas de acesso às instituições científicas em um periodo inicial de políticas públicas direcionadas à educação superior eà pesquisa científica, de que o Conselho Nacional de Pesquisa (CNPq) e a Coordenação de Aperfeiçoamento de Pessoal de Nivel Superior (CAPES), constituem um marco, ambos fundados em 1951. A relação entre uma estudante de escola secundária, Dyrce Lacombe, e o professor de ciências, Newton Dias do Santos, mostra que a partir da ampliação da escolarização de mulheres, a iniciação à ciência poderia começar antes mesmo da passagem pelo treinamento no ensino superior. Ela o conheceu em
1945, no Ginásio Mariz e Barros, logo após ele ter ingressado como naturalista no Museu Nacional.

Esse caso chamou a atenção em uma investigação a respeito da trajetória profissional de pesquisadoras do Instituto Oswaldo Cruz, que pertenceram à primeira geração de mulheres formadas nas faculdades de filosofia. Acompanhando o percurso cientifico realizado pela zoóloga Dyrce, que integrava esse grupo, percebemos a importância da iniciação científica precoce que recebeu do professor para o seu recrutamento e encaminhamento profissional para duas instituições científicas do Rio de Janeiro, o Museu Nacional e o Instituto Oswaldo Cruz. Mais do que isso, esse relacionamento relativamente duradouro, constitui uma chave para o entendimento das escolhas que ela fez e definiram os rumos da carreira. A análise contempla alguns aspectos dessa relação, e está delimitada temporalmente entre o momento em que se conheceram, e o ano de 1963, quando ela se afasta profissionalmente do professor ao deixar o posto de naturalista do Museu Nacional, onde havia ingressado para uma vaga de naturalista ao fazer um concurso público em 1957.

Este estudo tem como base a premissa segundo a qual esse relacionamento, que apresenta diferentes dimensões, se estabeleceu a partir de parâmetros de comportamento baseados em uma nova sociabilidade de gênero resultante da convivência entre estudantes e professores de ambos os sexos nos ambientes educativos e científicos do Distrito Federal. Trata-se, em nossa perspectiva, de uma extensão do fenômeno descrito por Trigo (1994) a respeito da sociabilidade acadêmica da Faculdade de Filosofia Ciências e Letras da Universidade de São Paulo, onde se formaram grupos mistos de estudo e trabalho que ensejaram uma nova sociabilidade acadêmica que mudou o padrão tradicional de rígida separação entre os sexos na vida familiar e pública.

Uma outra questão diz respeito ao papel desempenhado por Newton Santos na relação com a aluna e futura colega de trabalho. Não se tratava de uma ação de recrutamento nos moldes de um mentor tradicional, e sim semelhante a de um intelectual mediador cultural, especializado 
na "produção e comunicação de conhecimento, direta ou indiretamente vinculado à intervenção politico-social" (GOMES; HANSEN, 2016, p. 10). Em um sentido específico, designamos Santos como um cientista-professor mediador cultural para assinalar as múltiplas funções e posições acumuladas em sua trajetória profissional, caracteristica que compartilha com o intelectual mediador. Essas múltiplas funções e posições constituiam os principais atributos de sua ação dirigida para a formação de profissionais em educação e divulgação da ciência, em particular estudantes e professoras das instituições escolares. Pesquisador, professor, divulgador, produtor de livro didático e paradidático, museólogo, produtor de filmes, palestrante, entre outras habilidades profissionais, caracterizaram a versatilidade intelectual do cientista-mediador. Ele transitava em diversos espaços profissionais e associativos, desde as escolas secundárias, passando pelas escolas normais e faculdades, até museus e centros de pesquisa, entre outros, conformando um campo singular de ação. O cientista mediador cultural exibia qualidades distintivas e constitutivas da mediação cultural que praticava.

Em torno desses argumentos o texto se desenvolve, descrevendo inicialmente certos traços do perfil profissional de Newton Santos que o caracterizam como um cientista-professor mediador cultural. Na sequência apresentamos os momentos na trajetória de Dyrce Lacombe em que identificamos a interferência de Newton, e o comportamento dela diante dessa ação.

\section{Newton Dias dos Santos: cientista- professor e mediador cultural}

"O Museu Nacional não é só a Casa do povo, onde se instruem leigos, estudantes e professores, é também a casa da Ciência onde se estimulam, se despertame se aproveitam vocações científicas".

(Newton Dias dos Santos)
No obituário de Newton Santos (1916-1989), os entomologistas Ângelo Barbosa Machado (1934-2020) e Janira Martins Costa (1941-2018), o reconhecem como o "pai da odonatologia" brasileira - área da entomologia que estuda libélulas (odonatas). Ao longo da carreira de mais de 40 anos, publicou 127 artigos somente sobre os odonata, entre os quais consta a descrição de quatro gêneros, quarenta e nove espécies, e uma subespécie, todas brasileiras (MACHADO; COSTA, 1990). Os autores comentam que se os estudos sobre as libélulas conferiram prestígio internacional a Santos, o magistério não foi menos importante em sua trajetória profissional. Ele lecionou em várias instituições, do ensino médio ao superior. Ensinou zoologia, biologia educacional, metodologia do ensino de ciências biológicas, metodologia especial em zoologia e história natural. A importância que conferia ao ensino de ciências se traduz no manual intitulado Práticas de Ciências, publicado em 1955, e que, segundo os autores, "revolucionou o campo, abrindo uma nova era na metodologia para o ensino de ciências" no país. Por fim, lembram que Santos era famoso entre os estudantes da escola secundária, porque os levava a campo. Ele podia ser "visto nas florestas, rios e lagoas da cidade do Rio de Janeiro cercado de alunos entusiasmados e fascinados com seus métodos práticos e diretos de ensino" (MACHADO; COSTA, 1990, p. 299).

Esse depoimento dos ex-alunos e discipulos constitui uma sintese esclarecedora de como diferentes competências se misturam no perfil do mediador personificado por Santos: cientista, professor, autor de livros didáticos e manuais pedagógicos, divulgador científico. Ele transita de uma a outra atividade, articulando-as e orientando-as para um propósito. Salvo engano, esse propósito se explicita no trecho do discurso de posse que abre essa seção ao dizer que o Museu Nacional é uma casa para instruir leigos, estudantes e professores, e despertar vocações científicas. Essa declaração conduz à reflexão sobre como essa finalidade se traduziu em sua prática profissional 
como mediador cultural, especificamente no que tange ao recrutamento de estudantes para a carreira científica, em particular as mulheres.

No depoimento de Machado e Costa, eles assinalam o caráter inovador dos métodos de ensino do professor Santos nas aulas de ciências da escola secundária, aos quais atribuem o despertar de seu interesse pelas ciências. Essa lembrança conduz à chave da resposta à questão formulada sobre a forma de ação do cientista, professor e mediador cultural. Essa pressuposição encontra evidência no manual pedagógico, citado anteriormente, Práticas de Ciências: guia de ensino elementar, em que chama atenção a inscrição na folha de rosto: "Newton Dias do Santos. Doutor em História Natural. Naturalista do Museu Nacional. Professor da Escola Normal Carmela Dutra. Professor Catedrático do Instituto de Educação" (SANTOS, 1968). Nessa apresentação do autor observa-se o destaque conferido ao título de Doutor em história natural e às funções de pesquisador e de professor. Consta também o público ao qual se dirige: professores primários e secundários, alunos de escolas normais e secundárias e pais empenhados na aprendizagem dos seus filhos.

Os manuais pedagógicos e livros didáticos escritos por ele e por outros cientistas, como por exemplo, Cândido Firmino de Mello Leitão, zoólogo do Museu Nacional, tinham como finalidade prover o letramento científico de que professores e estudantes necessitavam para o aperfeiçoamento do exercício do magistério, e para a orientação às ciências. Essas obras destacavam a importância do conhecimento científico e o papel do professor na condução das aulas baseadas na experimentação. Nas palavras de Santos:

O aluno precisa assistir com seus olhos, senão realizar, essa maravilhosa transformação. Seus sentidos, em plena educação e desenvolvimento, precisam sentir a grandeza da ciência. E a professora terá esse glorioso privilégio de participar e cooperar no aperfeiçoamento de nossa cultura em incremento (SANTOS, 1972 , p. 189 apud MORAES, 2010, p. 189).
Nessa perspectiva, o ensino deveria promover o "espírito científico" entre os estudantes de forma a incentivar o gosto pelas ciências. A prática experimental em sala de aula constituia a melhor estratégia pedagógica para atrair jovens estudantes do secundário, e recrutar as "vocações científicas". Conforme Newton:

É, pois, fundamental iniciar os pré-adolescentes nesse mundo maravilhoso, deixar que se manifestem suas vocações e encaminhá- los no âmbito das ciências puras e aplicadas (SANTOS, 1972, p. 32 apud MORAES, 2010, p. 99).

Em outras palavras, educação baseada na ciência (conhecido experimentalismo pedagógico) é a fórmula eficaz para o recrutamento para a ciência. Tal como confirmam os discípulos citados anteriormente. Tratava-se, em última instância, de reproduzir e legitimar a própria ciência construindo e expandindo o seu público, pois, como acreditava Santos, além de "um fim em si mesma", ela consistia no meio "mais poderoso" de que o homem dispunha para o desenvolvimento humano (SANTOS, 1972, p. 32 apud MORAES, 2010, p. 99).

Embora não seja a intenção aqui tratar extensivamente da trajetória profissional de Santos, vale destacar alguns aspectos que auxiliam a compreensão de como essas convicções se formaram e presidiram suas práticas profissionais.

A primeira é a referência a Alberto Sampaio (1881-1946), chefe da Divisão de Botânica do Museu Nacional que foi seu professor na escola de ciências da Universidade do Distrito Federal (UDF). ${ }^{3}$ O primeiro contato deixou na memória do aluno a lembrança dos métodos empregados pelo professor e seu assistente:

A aula de botânica [...] fôra motivo de outro encantamento, sob a direção do ilustre mestre professor Alberto Sampaio, chefe da Divisão de Botânica do Museu Nacional, e um dos mais ilustres botânicos do Brasil. Sua primeira conferência, seguida de uma exibição cinematográfica, musicada e falada, foi uma demonstração cabal de que a botânica é, sem dúvida, a «sciencia amabilis» de Lineu, como era a sua expressão. [...] Assistido por Vianna Freire, excelente e inigualável nas aulas práticas, a botânica revelou-se uma esplêndida ciência, geralmente tida por enfadonha (SANTOS, 1945, p. 6). 
Chamamos atenção para os elementos didático-pedagógicos utilizados por Sampaio: cinema, música e oralidade. Trata-se de mediação cultural na medida que transpõe o conhecimento científico para outras formas de manifestação cultural (cinema, música e a narração) mais atraentes e enraizadas no cotidiano dos estudantes. Não se dispõe de informação a respeito da relação de ambos no Museu Nacional, mas certamente eles conviveram, pois Sampaio se aposentou em 1941, um ano após o ingresso de Newton por meio de concurso para naturalista interino. ${ }^{4}$ É provável que o botânico tenha orientado Newton para a seleção. Naquele momento, ele era um recém-formado professor de história natural na Escola de Ciências da UDF (1938), 5 e tinha conseguido um emprego como professor da prefeitura do Distrito Federal. Essa oportunidade para ingressar no quadro da Secretaria de Educação foi oferecida aos 18 formandos da primeira turma da Escola de Ciências, com o objetivo de incrementar a formação de professores de ciências no secundário e no ensino normal. ${ }^{6}$ Afinal, esse constituía um dos objetivos da Escola de Ciências, ao lado da formação teórica e prática de cientistas.

A passagem de Newton Santos pela UDF significou para o seu percurso de mediador o esteio de sua formação científica e intelectual. Ele se diplomou na primeira turma do Curso de História Natural da Escola de Ciências, sendo habilitado como professor e como bacharel em história natural. Criada em 1935, e extinta em 1939,7 a UDF constituiu um experimento educacional inovador, idealizado por Anísio Teixeira.

A instituição se propunha, entre outras atribuições culturais, a "encorajar a pesquisa cientifica, literária e artística", "formar profissionais e técnicos" e, especialmente, "prover a formação do magistério em todos os seus graus" (FÁVERO, 2000; MENDONÇA, 2002; PAIM, 1981, p. 78). No entanto, a prioridade foi concedida à formação de professores, especialmente para a escola secundária, estabelecendo-se de forma a "romper com a tradição", segundo a qual o ensino superior se reduzia à formação profissional de médicos, advogados e engenheiros (PAIM, 1981, p. 11). Ela era composta por cinco escolas - Ciências, Educação, Economia e Direito, Filosofia - e o Instituto de Artes. O curso de História Natural, no qual Santos se diplomou, era ministrado por cientistas e professores consagrados, que atuavam nas principais instituições científicas do Distrito Federal. Lauro Travassos, pesquisador do IOC, era responsável pela disciplina de zoologia; Alberto José Sampaio, do Museu Nacional, como mencionado anteriormente, ministrava as aulas de botânica; Djalma Guimarães, do Serviço Geológico e Mineralógico Nacional, atendia na disciplina de geologia. Todos esses eram membros da Academia Brasileira de Ciências. A escola contava também com cientistas e professores estrangeiros radicados no Brasil. Entre os de origem alemã constavam: o físico Bernard Gross, e os químicos Viktor Leinz e Otto Rother, do Instituto Nacional de Tecnologia; o químico Alfred Schaeffer da Escola Técnica do Exército.

Além dessas experiências, Santos foi exposto a uma formação pedagógica inovadora instituida pela Escola de Educação, a começar pela ausência de instalações próprias - laboratórios, bibliotecas, salas de aula. As aulas eram ministradas nos laboratórios dos professores nas instituições científicas às quais pertenciam. Não havia um campus universitário - ela era "uma universidade na cidade" (MENDONÇA, 2002, p. 124-135). Essa configuração favorecia a formação

\footnotetext{
Santos se tornou naturalista efetivo em 1943

5 Antes de entrar na UDF em 1935. Santos foi estudante da Faculdade de Medicina, onde ingressou em 1934. Ele comenta esse curso se revelou uma grande decepção ao enfatizar o ensino expositivo em detrimento do experimental. Dado que seu interesse era a pesquisa biológica experimental, resolveu abandonar a medicina, e entrou na recém-criada Escola de Ciências da UDF, configurada de modo "revolucionário" para o Brasil. Apesar disso, ele se formou em medicina em 1940 (SANTOS, 1945, p. 6).

6 Dentre esse grupo constavam diplomados que destacaram posteriormente na carreira cientifica, tais como: Oswaldo Frota-Pessoa, geneticista da Faculdade Nacional de Filosofia (FNFI) da Universidade do Brasil, e da Faculdade de Filosofia Ciências de Letras da Universidade de São Paulo (USP); Alcides Lourenço Gomes, zoólogo do Serviço de Pesquisa em Piscicultura do Ministério da Agricultura; Domingos Arthur Machado Filho, médico, veterinário e helmintologista que ingressou em 1935 no IOC; José Antunes, José Lacerda de Araújo Feio, Luiz Emidio Melo Filho e Emanuel de Azevedo Martins, todos do Museu Nacional (PAIM, 1981, p. 77-78).

7 Com a extinção, parte do quadro docente e de sua proposta pedagógica foram incorporados à Universidade do Brasil, mais especificamente na Faculdade Nacional de Filosofia, Ciências e Letras (FNFi) (PAIM, 1981; MENDONÇA, 2002).
} 
teórica e as práticas de laboratório dos estudantes, baseadas no experimentalismo pedagógico, segundo o qual se aprende ciência fazendo ciência no laboratório ou na pesquisa de campo. Essa orientação corroborava os preceitos e o programa da Escola de Educação, estruturado em três partes: curso de conteúdo (matérias especificas de cada curso, por exemplo história natural); curso de fundamentos (matérias de cultura geral, por exemplo linguas estrangeiras); e curso de integração profissional (matérias de educação, por exemplo, sociologia da educação).

A socialização nesse ambiente deixou marcas indeléveis na formação intelectual de Newton Santos. Tratava-se de uma experiência inovadora em termos de ensino superior, baseado em parâmetros científicos tanto em termos do perfil do corpo docente, quanto das práticas de ensino-aprendizagem. Nesse sentido, não foram fortuitas as articulações que ele estabeleceu em sua atuação profissional entre diferentes áreas de atividades.

Um outro aspecto a assinalar na trajetória de Santos é o vínculo com a educação em ciências naturais e a divulgação cientíica. Esse vínculo se estabeleceu inicialmente pelas próprias finalidades do Museu Nacional nesses campos, principalmente a partir da direção de Edgar Roquette-Pinto (1926-1935), que criou, em 1927, o Serviço de Assistência ao Ensino (SAE) de história natural, cuja principal finalidade era a de oferecer cursos para professores de todo o país para a organização de gabinetes de história natural, museus escolares e herbários (DUARTE, 2010, p. 88). ${ }^{8} \mathrm{O}$ interesse de Santos por essas atividades se consolidou ao assumir a chefia do Serviço de Extensão Cultural (SEC) entre 1957 e 1958.9 Nessa função, durante o ano de 1958, Newton proferiu palestras e conferências sobre ensino de ciências em reuniões e congressos, participando da fundação da Associação dos Professores de Ciências do Distrito Federal. ${ }^{10}$ Realizou também cursos de aperfeiçoamento em ciências para professores secundários do Colégio Pedro II, do Instituto de Educação, do Colégio Nova Friburgo, do Colégio Lafayette, entre outros. Além disso, coordenou excursões para professores a localidades no próprio Distrito Federal, e em cidades do interior do Estado do Rio de Janeiro, como Arraial do Cabo e Cabo Frio. A execução dessas ações do SEC contava com a parceria e o apoio de várias instituições governamentais, tais como: Instituto Nacional de Pesquisas e Estudos Educacionais (INEP); Conselho Nacional de Pesquisa (CNPq); Coordenação de Aperfeiçoamento de Pessoal de Nivel Superior (CAPES); Campanha de Aperfeiçoamento e Difusão do Ensino Secundário (Cades). ${ }^{11}$ Nesse período, Santos estreitou os vínculos com as ações de educação ao assumir a função de coordenação da área de ciências da Cades, que mantinha uma colaboração regular com o SEC em vista da finalidade comum de aperfeiçoamento técnico de professores do ensino secundário.12 Durante o periodo em que assumiu a direção do Museu Nacional (1961-1963), ele manteve as ações educativas, realizando cursos de aperfeiçoamento em ciências para professores secundários em Fortaleza e Belo Horizonte, contratados pela Cades. ${ }^{13}$ Em 1962.

\footnotetext{
8 O SAE disponibilizava a sala de cursos para professores primários e secundários ministrarem aulas aos alunos, utilizando material científico, didático e visual (gravuras, filmes e diapositivos) elaborados pelo Museu. O serviço oferecia também assistência às escolas na conservação de materiais biológicos coletados pelos alunos, e enviados para o tratamento pelos especialistas do Museu, que os devolviam para serem utilizados nas aulas de ciências naturais. Entre 1927 e 1933, foi registrada a frequência no SAE de 16.298 alunos e professores, e a realização de 340 aulas, cursos e conferências. As escolas enviaram cerca de 6000 mil materiais coletados para tratamento pelo Museu (SILY, 2012, p. 318).

9 O SEC foi criado em 1941 durante a gestão de Heloísa A. Torres (1938-1955). Santos liderou um grupo de naturalistas que fizeram oposição à diretora, que foi acusada por ele de descontinuar as ações educativas estabelecidas por Roquette-Pinto (SANTOS apud OLIVEIRA, 2013, p. 53: CORRÊA, 1997, p. 42).

10 Pelo regimento interno de 1958 o SEC foi elevado na estrutura administrativa à condição de Divisão de Educação. UNIVERSIDADE DO BRASIL, MUSEU NACIONAL. Relatório Anual-1958. José Candido de Melo Carvalho (diretor), 1959.

11 UNIVERSIDADE DO BRASIL, MUSEU NACIONAL. Relatório Anual-1958. José Candido de Melo Carvalho (diretor), 1959.

12 A CADES foi criada pelo decreto $n^{\circ}$ 34.638, de 17 de novembro de 1953 , subordinando-se a Diretoria do Ensino Secundário do Ministério da Educação e Cultura. Ela surgiu para atender a demanda por professores para o ensino secundário, em vista do amplo crescimento desse a partir da década de 1940. Propunha-se a investir no aperfeiçoamento e na formação de docentes em regiões que não dispunham de profissionais licenciados pelas faculdades de filosofia (PINTO, 2008).

13 Newton Santos publicou 43 artigos na área de educação e divulgação cientificas. Com o geneticista Oswaldo Frota-Pessoa, e Ayrton Gonçalves da Silva, ex-colegas da UDF, editou um suplemento semanal no jornal A Manhã chamado "Ciência para Todos" (CPT), que circulou entre 1948 e 1953 (ESTEVES; MASSARANI; MOREIRA, 2006, p. 69)
} 
Santos promoveu e ministrou aulas no curso para treinamento de guias de museus, orientado para ensinar professoras primárias do estado da Guanabara a utilizar as exposições do Museu. ${ }^{14}$

Ao lado das atividades no Museu Nacional, o magistério constituiu indubitavelmente uma plataforma fundamental para sustentar os projetos e as práticas de mediação cultural. Santos havia feito carreira nos colégios Visconde de Mauá e Pedro II, na Escola Normal Carmela Dutra, e no Instituto de Educação do Rio de Janeiro (antigo Distrito Federal), todos estabelecimentos públicos importantes para a história de educação no Rio de Janeiro e no Brasil. Ele também lecionou em estabelecimentos particulares, como os colégios Paiva e Souza e Felisberto de Menezes, escolas que tinham como público-alvo jovens oriundos da classe média da zona norte carioca (bairro da Tijuca). No ensino superior foi professor da Faculdade de Filosofia da Universidade da Guanabara (ex-Instituto La-Fayette e atual Universidade do Estado do Rio de Janeiro), e na Faculdade de Filosofia da Fundação Universitária Gama Filho (atualmente extinta).

Confrontando a importância institucional e simbólica desse conjunto de instituições, percebe-se que o magistério secundário exerceu maior influência do que o ensino universitário em sua trajetória profissional, notadamente as práticas pedagógicas de mediação cultural que visavam a formação e o aperfeiçoamento de professores "autodidatas" e de leigos, tornando-os legalmente habilitados para o exercício de magistério secundário. Tratava-se de práticas institucionalizadas a partir da implementação de políticas públicas de educação cujo alvo era o ensino secundário. A expansão acelerada do número de escolas e de matrículas nas décadas de 1940 e 1950 evidenciou um escasso quantitativo de professores, bem como o seu despreparo pedagógico. Os licenciados egressos das faculdades de filosofia, ciências e letras, que deveriam atuar como professores de matemática, física, química, biologia, história, geografia e letras nas escolas secundárias - boa parte constituida por mulheres -, constituiam uma pequena minoria. Até então, os professores desse nivel de ensino eram "autodidatas", não tinham recebido nenhuma formação específica que os capacitasse ao exercício do magistério. Eles eram médicos, engenheiros, advogados, militares, bacharéis em letras do Colégio Pedro II, ou diplomados pela escola normal, que, formalmente, conferia habilitação para o ensino nas escolas primárias. Para tentar remediar o problema, em 1946, de forma emergencial, os professores começaram a ser recrutados por meio do exame de suficiência. ${ }^{15}$ O candidato, quando aprovado, obtinha o direito de lecionar nas regiões onde não houvesse professores habilitados por faculdades de filosofia ${ }^{16}$. A realização desse exame foi posteriormente assumida pela Cades, que passou a oferecer a licença para o ensino nas escolas secundárias.

\section{Dyrce Almeida Lacombe: trajetória de recrutamento e formação de uma cientista}

Dyrce Lacombe nasceu no Rio de Janeiro em 1932 em uma familia de classe média baixa. Os pais eram funcionários públicos de baixo escalão na Estrada de Ferro Central do Brasil. Logo após o seu nascimento, o pai foi transferido para a cidade de Mendes, no interior do estado do Rio de Janeiro, onde ela passou parte da infância e concluiu o ensino primário em uma escola pública. Ela conheceu o professor de ciências Newton Santos no Ginásio Mariz e Barros, escola pública localizada no tradicional bairro da Tijuca na zona norte do Rio de Janeiro, em meados da década de 1940, quando frequentava o ginasial.

Em entrevista concedida em 1999, ela comenta a relação que estabeleceu, quando era uma jovem estudante do ginásio, com o professor-cientista, que, como visto anteriormente, desde a década de 1930, se engajara no movimento de reforma educacional que preconizava que as ciências deveriam ser ensinadas aos estudantes não apenas nos ambientes escolares, mas

\footnotetext{
4 UNIVERSIDADE DO BRASIL, MUSEU NACIONAL. Relatório Anual-1962. Newton Dias dos Santos (diretor), 1962. 
também nas próprias instituições científicas. Não podemos aferir como o ensino de ciências foi efetivamente ministrado no Ginásio Mariz e Barros, mas sabemos das convicções pedagógicas de Santos, que, como salientam os discipulos Machado e Costa, citados anteriormente, se empenhava para que o ensino estimulasse o interesse dos estudantes pela experimentação científica. O depoimento da aluna dá pistas desse compromisso do professor:

E eu cada vez mais entusiasmada com aquilo. Cada vez mais. Ele gostava daquilo de me ver assim. E começou a perguntar: "por que você não faz pesquisa?" E eu disse: "ah! eu queria, sim, mas não tenho dinheiro". "Não, faça!" Ele facilitou o laboratório dele para mim, e eu comecei no Museu Nacional vendo libélulas, uma coisa e outra (LACOMBE, 1999).

Ao que parece a primeira atitude de Newton Santos foi garantir as condições materiais minimas para que a jovem aluna pudesse prosseguir com sucesso os estudos:

Ele me deu muito apoio. Nós éramos muito pobres, muito pobres mesmo [...]. Ele era professor do colégio Mariz e Barros e começou a me dar apoio em tudo, livros que eu não podia comprar, caderno, eu não tinha nada disso. [...] Quando cheguei no científico eu fiquei mais entusiasmada [com a ciência], e o Newton viu isso e aproveitou o meu entusiasmo (LACOMBE, 1999).

Esse apoio material - livros, cadernos, ensino secundário em uma escola privada tradicional e aulas particulares de preparação para o vestibular - foi imprescindivel para que a estudante conseguisse obter uma sólida formação escolar que a capacitasse a prestar com sucesso o exigente e concorrido exame vestibular para a Faculdade Nacional de Filosofia, Ciências e Letras (FNFi) da Universidade do Brasil (atual UFRJ). Mas havia também um outro sentido na relação que se estabeleceu entre o professor e a aluna: uma forte afinidade social. Newton Santos foi aluno de escolas suburbanas nos bairros de Todos os Santos (adjacência do Meier) e Cascadura no Rio de Janeiro, onde estudou no tradicional Colégio Arte e Instrução. Dyrce também residia no subúrbio, no Meier, quando conheceu o professor de história natural. Há indícios de que foi Newton Santos quem a encaminhou para fazer o curso científico (ensino secundário) no renomado Colégio Arte e Instrução de Cascadura. As identidades sociais entre eles eram marcantes: a origem suburbana, de classe média baixa, e a escolarização em colégios da zona norte do Rio de Janeiro. Para ambos a educação se apresentava como uma via de mobilidade social. A complementação e o reforço da formação escolar de Dyrce dependeu, em parte, do apoio de seu professor que a percebia como uma candidata potencial ao recrutamento para o magistério e para a carreira científica. No seu certificado de habilitação do ginásio, a nota mais alta é 9.8 em ciências naturais, além de ser uma aprovação com quase 100\% de aproveitamento. ${ }^{17} \mathrm{O}$ bom desempenho da aluna e o interesse do professor por ela podem ser interpretados como uma via de mão dupla. É possivel que ela tenha se dedicado à disciplina do professor com quem tinha mais afinidade, somando-se à sua declarada preferência pelas ciências desde muito cedo. Em contrapartida, o interesse e o desempenho dela em ciências estimularam o professor a prosseguir em sua "missão" como mentor, passando a incentivá-la a ingressar na universidade.

Na Imagem 1 podemos perceber indícios das relações entre Newton e as alunas do Ginásio Mariz e Barros. Na fotografia o professor está no centro rodeado apenas por meninas, entre elas aquela na qual ele investiu na formação, Dyrce Lacombe (a primeira da esquerda para direita). 
Imagem 1 - Professor Newton Santos e alunas do Ginásio Mariz e Barros

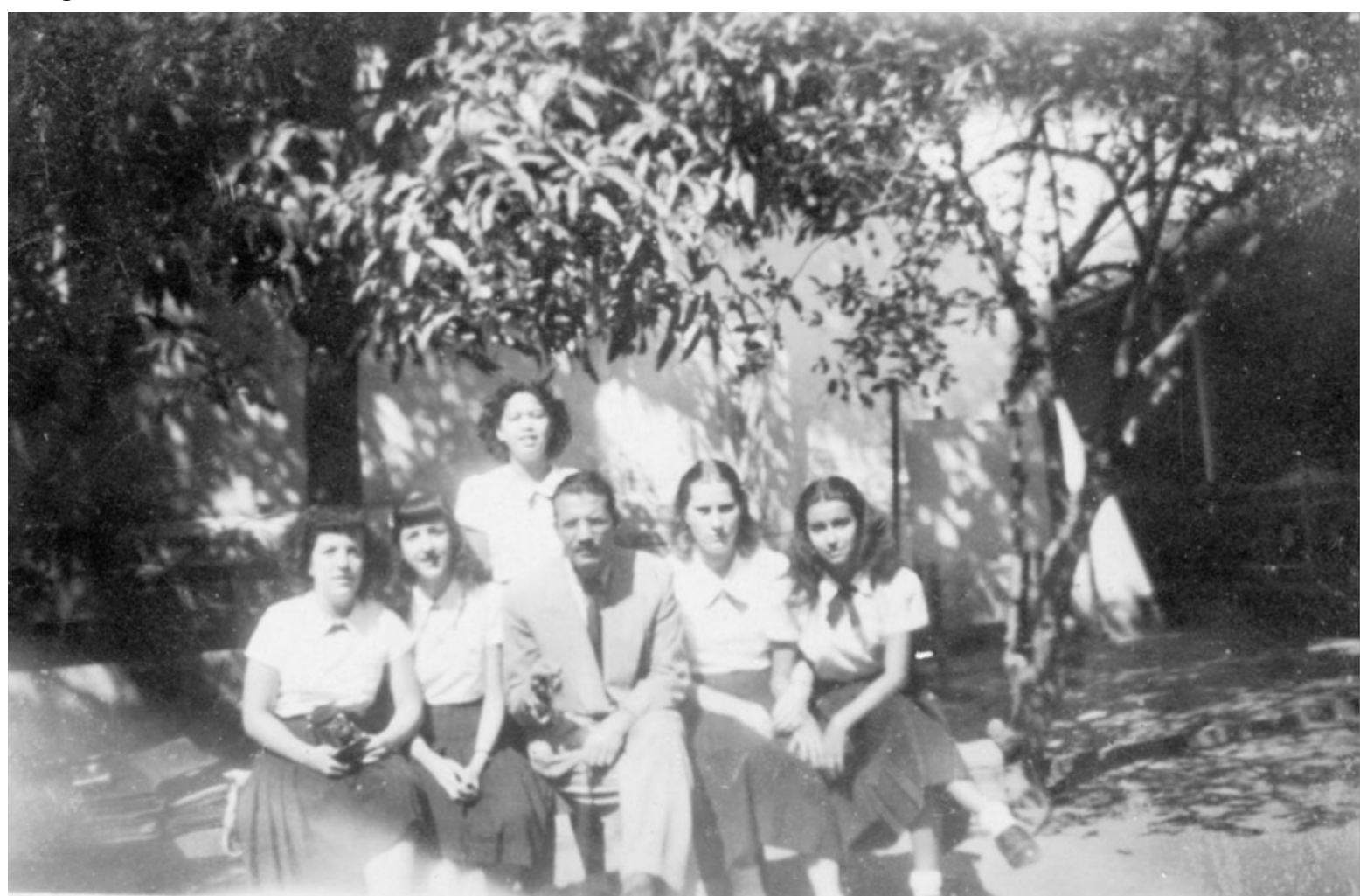

Fonte: Acervo pessoal Dyrce Lacombe, [194-].

Legenda: Newton Santos (ao centro), Dyrce Lacombe (a primeira à direita) e alunas do Mariz e Barros - Tijuca, RJ, final dos anos 1940.

Na sequência da formação de Dyrce, o curso científico (nivel secundário) realizado no Colégio Arte e Instrução, proporcionou a ela um aprendizado consistente em ciências. Adicionalmente, ela passou a acompanhar as atividades de ensino de ciências do Museu Nacional pela indicação de Newton Santos, enquanto a preparava para prestar o exame vestibular. Nesse periodo, ela acompanhou o curso de extensão que ele ministrava de segunda a sexta-feira, das $13 \mathrm{~h}$ às $16 \mathrm{~h}$. $O$ curso com duração de três semanas, e vagas limitadas a 30 alunos,$^{18}$ tratava de técnicas de levantamento biológico e planejamento. E integrava as ações de mediação cultural com vistas a atingir uma clientela e objetivos especificos: preparar estudantes e professores (homens e mulheres) para o magistério das disciplinas científicas no ensino secundário. A estratégia pedagógica adotada era a do envolvimento dos alunos em atividades de pesquisa, o principal preceito pedagógico do projeto de educação em ciências promovido pelo Museu Nacional durante três décadas (de 1940 a 1960). Como comentado anteriormente, essa atividade voltada para os professores do ensino secundário contou com o apoio da CADES, o que transformou as ações de mediação cultural da instituição em instrumento de política pública com alcance nacional. 
Nesse mesmo ano de 1950, o professor recomendou também que Dyrce seguisse o curso de especialização em Entomologia Geral do IOC, ${ }^{19}$ ministrado pelo pesquisador Rudolf Barth. ${ }^{20}$ Quando ela foi se inscrever, percebeu o inusitado da situação em que se encontrava:

Foi uma coisa gozada, porque eu ainda não era de faculdade. Quando eu cheguei lá para me inscrever disseram: "não pode minha filha, isso é só para universitário, e você não é". Eu respondi: "Mas eu vou passar para a faculdade!" "É, mas não dá, fala com o diretor". Era o dr. Olympio da Fonseca. Eu fui lá e ele disse assim - ele viu a vontade que eu tinha de fazer o curso, de entrar -: "Olha, vamos fazer uma coisa. Faz o curso, mas vai fazer a faculdade. Se por acaso você não entrar, imediatamente sai do curso, está bem?" E eu disse: "tá, tá bom". Eu dei sorte! Passei em primeiro lugar! (LACOMBE, 1999)

Assim, por intermédio do professor, a estudante da segunda série do curso científico teve acesso a cursos de extensão e de especialização (nivel de pós-graduação nos termos atuais) em duas das mais importantes instituições acadêmicas do Distrito Federal naquele periodo. Embora essa fosse uma situação incomum, como a própria Dyrce assinala ao dizer que "não era de faculdade", parece que o professor Santos pretendia expô-la prematuramente ao ambiente de pesquisa, avaliando, provavelmente, que ela desfrutaria dessa experiência em função do desempenho escolar que apresentava. A influência de Newton na vida escolar da aluna não se restringiu à preparação para o exame vestibular, estendendo-se à indicação do curso universitário. Ela conta que gostaria de fazer medicina, mas foi dissuadida a optar pela história natural:

Eu não tinha dinheiro para entrar numa faculdade de Medicina. Aqueles livros... O Newton mesmo disse para mim: se você fizer medicina, eu não tenho como ajudar. Então, eu entrei para a Nacional. Lá se estudava física, química, matemática, geologia, botânica, e zoologia até com o Mello Leitão! (LACOMBE, 1999).

Como mencionado anteriormente, ele próprio havia abandonado a medicina pela história natural na UDF. Apesar de ter concluído o curso de medicina, não seguiu a profissão. É provável também que algum estímulo para a mudança de opinião dela tenha sido o curso do IOC, em que ingressou sob a condição imposta pelo diretor de obter a aprovação no vestibular para a história natural. Em 1952, Dyrce prestou vestibular em história natural para a Faculdade Nacional de Filosofia (FNFi) e a Faculdade de Filosofia do Instituto La-Fayette. ${ }^{21}$ Foi aprovada em ambas. Embora ela quisesse seguir seu mentor e ingressar nesse último Instituto, onde ele lecionava, optou pela primeira. De acordo com seu depoimento, essa escolha decorreu também das ponderações do professor a respeito dos custos de uma instituição privada como o La-Fayette. A FNFi não somente era pública, mas também dispunha de um corpo docente de excelência acadêmica, como o renomado catedrático de zoologia Cândido Firmino de Mello Leitão, ${ }^{22}$ também pesquisador do

\footnotetext{
19 Newton Santos havia se aproximado do IOC quando era estudante da UDF, onde conheceu Lauro Travassos, zoólogo de renome internacional, com quem iniciou "as primeiras investigações em zoologia" no IOC. Conforme seu relato, "ao receber o diploma da UDF" [...] "eu começava a ingressar numa outra escola, a "escola do professor Lauro Travassos, celeiro de numerosos zoólogos hoje espalhados pelo país. A Universidade tinha cumprido sua dupla promessa: a formação do professor e do pesquisador" (SANTOS, 1945, p. 7.).

20 Rudolf Barth (1913-1978) estudou zoologia na Universidade de Bonn (1932-1935), obtendo em 1937 o grau de doutor em zoologia nessa universidade. Imigrou para o Brasil em 1950, quando ingressou no IOC, e se tornou posteriormente chefe da Divisão de Zoologia Médica. Ele publicou mais de 190 artigos científicos (SCHATZMAYR, 2001).

${ }^{21}$ Em 1950, a Faculdade de Filosofia, Ciências e Letras do Instituto La-Fayette foi fundida à Faculdade de Ciências Econômicas do Rio de Janeiro, a Faculdade de Direito do Rio de Janeiro, e a Faculdade de Ciências Médicas, dando origem a Universidade do Distrito Federal (UDF) (homônima da universidade criada por Anísio Teixeira). Em 1959, passou a ser denominada Universidade do Rio de Janeiro, e, em 1961. Universidade do Estado da Guanabara (UEG). Em 1975, em decorrência da fusão entre os estados da Guanabara e do Rio de Janeiro, a universidade foi denominada Universidade do Estado do Rio de Janeiro (UERJ), nome atual. Informações disponiveis em: http://www. educacao.uerj.br/historico.html. Acesso em: 23 jul. 2021.

22 Mello Leitão foi pesquisador do Museu Nacional do Rio de Janeiro e professor de instituições escolares. Ocupou a cadeira de professor de História Natural na Escola Normal de Niterói no período de 1923 a 1931; foi docente da mesma disciplina na Escola Normal do Rio de Janeiro durante seis meses, em 1916, e no período de 1922 a 1930; atuou como professor de Biologia Geral, na Escola Secundária do Instituto de Educação (1934-1937); de Zoologia Geral e Sistemática, na Escola Superior de Agricultura, onde atuou como docente de 1913 até sua aposentadoria; de Zoologia, no Museu Nacional do Rio de Janeiro (1931-1937) e na Faculdade Nacional de Filosofia da Universidade do Brasil (1939-1941). Também foi membro da Associação Brasileira de Educação, da Associação Brasileira de Ciências - como vice-diretor no periodo de 1937 a 1939 e presidente em 1943 a 1945 -, da Academia Nacional de Medicina na década de 1920, presidente do Conselho de Caça e Pesca em 1935 e atuou como membro na Comissão Nacional do Livro Didático na década de 1940 (SPIGUEL; SELLES, 2013, p. 117).
} 
Museu Nacional, e muitos estrangeiros (FAVERO; PEIXOTO; SILVA, 1991).

O fato é que, como ela própria comenta, o curso universitário the proporcionou a continuidade das experiências de formação científica que vinha recebendo, bem como a chance de ampliar os conhecimentos, uma vez que, além de história natural, a área de ciências abrangia os cursos de Física, Química, Geologia, Meteorologia e Astronomia. Contudo, ela relata que, durante o primeiro ano, para conciliar as aulas com o curso do IOC, deixou de almoçar para pagar o transporte, uma vez que os recursos dados pela mãe eram insuficientes. Sabendo dessas dificuldades financeiras, o diretor Olympio da Fonseca resolveu the conceder um auxilio à título de bolsa, convidando-a também para permanecer na instituição em face do bom desempenho no curso de Entomologia. Assim, a partir de 1953, ela ingressou como estagiária no laboratório de Barth, com quem havia feito o curso (LACOMBE, 1999). Ao concluir, em 1955, o bacharelado e a licenciatura na FNFi, Dyrce partiu para uma expedição à Bolívia, liderada pelo "insuperável mestre" Lauro Travassos, e integrada por uma equipe composta por pesquisadores do $\mathrm{IOC}$ e do Museu Nacional - Rudolf Barth, Haroldo Travassos (filho de Lauro) e Dalcy de Albuquerque. Ao retornar permaneceu com Barth, com quem, segundo ela, adquiriu o treinamento em anatomia e histologia de invertebrados, ${ }^{23}$ especialidade na qual seria reconhecida futuramente. ${ }^{24} \mathrm{Em} 1956$. ele a convidou para atuar como assistente no curso de Entomologia. ${ }^{25}$

Em 1957, por sugestão de Newton Santos, que nessa época chefiava o Serviço de Extensão Cultural (SEC), ${ }^{26}$ Dyrce prestou concurso público para a vaga de naturalista no Museu Nacional. De acordo com o relatório do Departamento
Administrativo do Serviço Público (DASP) de 1958, 27 o concurso, cujo edital foi lançado em 1957, tratava de vaga de naturalista-auxiliar do Ministério da Educação e Cultura, com lotação no Museu Nacional, e teve 26 candidatos inscritos. A realização de concursos públicos para o preenchimento de cargos técnico-científicos em instituições federais foi mais frequente no final dos anos 1950 e início dos anos 1960. Tratava-se de um processo relacionado à institucionalização da carreira de pesquisador que atendia a uma reinvindicação antiga da comunidade cientifica brasileira. Também sinalizava uma transição geracional que promovia a substituição da geração de cientistas, professores e técnicos que havia ingressado no serviço público durante a década de 1930. Uma das caracteristicas dos concursos públicos realizados nesse contexto foi a presença de mulheres egressas de cursos superiores ministrados nas universidades públicas, que vinham sendo criadas desde a década de 1930, sobretudo as diplomadas nos cursos de história natural que eram predominantemente frequentados por mulheres (AZEVEDO; FERREIRA, 2006). Não por acaso, junto com Lacombe, se inscreveram outras 11 mulheres, representando quase $50 \%$ dos concorrentes. Em 1958, o resultado foi publicado no Diário Oficial, constando dez aprovados, metade mulheres: Dyrce Lacombe, Wilma Teixeira Ormond, Leda Dau, Marilia Carvalho de Mello e Alvim, e Myriam Chapot Prevost Gino, 28 todas elas, a exceção de Dyrce, seguiram carreira no Museu Nacional.

Lacombe foi aprovada para a SEC, que, em 1958, se transformou em Divisão de Educação. Depois de um longo relacionamento do tipo "mestre e aprendiz", Newton Santos e Dyrce Lacombe se tornaram pares, ou seja, cientistas pertencentes ao quadro da mais tradicional e

\footnotetext{
23 No campo da entomologia, ela desenvolveu com Barth uma linha de pesquisa em histologia de barbeiros. Em 1956, ela participou de expedições ao interior de Minas Gerais para coletar esses insetos em cafuas. No ano seguinte, fez excursões a Foz do Iguaçu, Argentina e Paraguai para coletar material biológico para estudos histológicos.

24 Ela ampliou o treinamento em histologia no laboratório de Antonio Couceiro no Instituto de Biofísica da Universidade do Brasil (atual Universidade Federal do Rio de Janeiro).

25 Até a década de 1960 ela manteve apenas um vínculo estável no âmbito da docência: o Instituto La-Fayette, onde ingressou em 1958 a convite de Olympio da Fonseca para ser instrutora e, posteriormente, assistente da cadeira de biologia geral.

26 UNIVERSIDADE DO BRASIL, MUSEU NACIONAL. Relatório Anual-1958. José Candido de Melo Carvalho (diretor), 1959, p. 36.

27 DEPARTAMENTO ADMINISTRATIVO DO SERVIÇO PÚBLICO. Relatório das atividades do DASP-1957. Serviço de Documentação, 1958 , p. 42.

28 BRASIL. Presidência da República, Diário Oficial: seção I, p. 27754, 11 dez. 1957.
} 
longeva instituição científica do país. No entanto, a aprovação no concurso não significou que sua carreira como cientista estivesse definitivamente vinculada ao Museu Nacional. Ela não permaneceu ali por muito tempo, se exonerando em 1963 após ser incorporada ao IOC no cargo de biologista. O que explica a sua disposição para deixar o Museu Nacional?

Como mencionado anteriormente, foi por intermédio de Newton Santos que Dyrce estabeleceu vínculos com o IOC, e se inseriu em uma rede de cientistas com grande prestígio nacional e internacional. A Divisão de Zoologia Médica, da qual fazia parte o laboratório de Barth, era chefiada por Lauro Travassos, considerado o fundador de uma "escola brasileira" de zoologia (helmintologia e entomologia) reconhecida internacionalmente (ZARUR, 1994, p. 99-132). Aqui observa-se, mais uma vez, a similaridade entre a trajetória de ambos. Já foi mencionado anteriormente que Santos se reconhecia como discípulo de Travassos. Foi no laboratório desse que ele, primeiro, e depois Dyrce, receberam treinamento em zoologia. Ela comenta essa relação e nomeia os demais pesquisadores com quem começou o aprendizado científico:

Tive a oportunidade de aprender com os grandes mestres: Lauro Travassos - a técnica de fixação, clarificação e acondicionamento de helmintos; Rudolf Barth: coleta, classificação, fixação para histologia de todo material entomológico; Harold Travassos: a parte referente aos peixes e batráquios; Dalcy de Albuquerque: toda anatomia de Dipteros. ${ }^{29}$

A reconstituição de processo de formação e profissionalização científica da zoóloga mostra que ela não tinha interesse pela educação em ciências justamente a atividade que constituía o cerne da prática de mediação cultural realizada pelo seu mentor. Ela se importava mais com a pesquisa no IOC do que com as atividades educativas para as quais fora designada a executar como naturalista e professora da Divisão de Educação. Esse desinteresse logo se manifestou em períodos de ausência do Museu, notados e comentados pelos demais colegas. E, apesar da relação que mantinha com Dyrce, Santos ao assumir a direção do Museu reagiu, descontando de seu salário os dias em que "estagiava" com Barth no IOC. Ela própria relata a situação e a escolha que fez:

\begin{abstract}
Eu trabalhava lá com o Newton. Ele era o diretor. Mas eu queria o Instituto Oswaldo Cruz. Eu fugia de lá e vinha para cá [IOC] [...] Ficaram pressionando o Newton, falando, e ai ele começou a cortar [salário]. Houve um congresso em Washington e ele cortou os dias em que eu estava lá. Ele estava danado da vida que eu vinha para o Instituto. "Quer saber de uma coisa? Eu não fico aqui, pronto. Eu vou para lá!" (LACOMBE, 1999).
\end{abstract}

O processo de transição para o IOC, que representou o início do afastamento do antigo mentor, parece ter começado logo após o concurso. Nos relatórios dos diretores do Museu entre 1958 e $1963^{30}$ a respeito das ações da Divisão de Educação constam poucas referências às atividades exercidas pela naturalista. O Quadro 1 mostra que as excursões zoológicas e os cursos de formação de professores de ciências naturais, patrocinados pela CADES, pelos quais ela era responsável, foram as atividades mais frequentes.

29 Trecho extraído do Acervo da Casa de Oswaldo Cruz, Fundo Dyrce Lacombe, ref. DL-FC-ST-24.

30 Entre 1958 e 1963, periodo em que Dyrce esteve no Museu Nacional, ele foi dirigido por José Candido de Mello Carvalho (1955-1961) e Newton Dias dos Santos (1961-1963). UNIVERSIDADE DO BRASIL, MUSEU NACIONAL. Relatório Anual-1958. José Candido de Melo Carvalho (diretor), 1959; UNIVERSIDADE DO BRASIL, MUSEU NACIONAL. Relatório Anual-1962. Newton Dias dos Santos (diretor), 1962. 
Quadro 1 - Atividades de Dyrce Lacombe no Museu Nacional ${ }^{31}$

\begin{tabular}{|c|c|c|}
\hline Ano & Atividades docentes & Expedições \\
\hline 1958 & Curso de ciências naturais CADES - Vitória da Conquista/BA & \\
\hline 1958 & Professora ciências naturais CADES - Bauru/SP & \\
\hline 1958 & & $\begin{array}{l}\text { Excursão ao Pará e } \\
\text { arredores (IOC) }\end{array}$ \\
\hline 1959 & & $\begin{array}{l}\text { Excursão a Itatiaia e Angra } \\
\text { dos Reis (Portaria do MN) }\end{array}$ \\
\hline 1960 & & $\begin{array}{l}\text { Excursão ao Brasil-Central } \\
\text { (Portaria MN) }\end{array}$ \\
\hline 1960 & & $\begin{array}{l}\text { Excursão aos arredores do } \\
\text { estado do RJ (Portaria do MN) }\end{array}$ \\
\hline Dez./1962 & Professora de Ciências Naturais CADES - Curitiba/PR & \\
\hline Fev./1962 & $\begin{array}{l}\text { Professora de Didática de Ciências no Curso de Orientação } \\
\text { aos exames de suficiência }\end{array}$ & $\begin{array}{l}\text { Excursão para Vitória da } \\
\text { Conquista para coleta de } \\
\text { material entomológico por } \\
40 \text { dias sem ônus ao MN }\end{array}$ \\
\hline 1963 & & $\begin{array}{l}\text { Excursão a Região } \\
\text { Amazônica pelo MN }\end{array}$ \\
\hline
\end{tabular}

Fonte: Elaborado pelos autores com informações extraidas do currículo de Dyrce Lacombe.

Em contrapartida, as publicações de Dyrce entre $o$ ano em que se formou na Faculdade e 1970, evidenciam a importância que conferia a atividade que exercia no IOC, apesar do caráter precário como bolsista, condição em que permaneceu por muitos anos. O Quadro 2 mostra em primeiro lugar que na maioria dos artigos ela é a única autora. Os poucos artigos em coautoria foram escritos com os pesquisadores do IOC. Em segundo lugar, o destaque da revista Memórias do Instituto Oswaldo Cruz mostra o estreitamento de laços com a instituição. Apenas dois artigos foram publicados no Boletim do Museu Nacional e, nesse caso, nenhum deles em coautoria com Newton Santos. Os demais periódicos indicam os vinculos acadêmicos que ela estabeleceu a partir de seu trabalho de pesquisa no IOC. Ela publicou em 1965 um artigo nos Anais da Aca- demia Brasileira de Ciências um ano depois de ser eleita - com certa precocidade, pois completava apenas nove anos de formada - como membro associado na seção de ciências biológicas. ${ }^{32}$ A referência ao Instituto de Pesquisa da Marinha, vale notar, remete a uma nova fase de sua carreira, quando ela definiu uma linha de investigação própria em zoologia marinha. Essa oportunidade apareceu quando ela começou a trabalhar com Barth nesse Instituto em 1965. Ali ela se especializou no estudo de cracas, sendo convidada pelo diretor do Instituto em meados da década de 1970 a analisar a ação corrosiva desses crustáceos sobre os pilares da ponte Rio-Niterói. Os investimentos que fez nessa nova linha de pesquisa a levariam para o Osborn Laboratories of Marine Science e o New York Aquarium, onde a partir de 1967 realizou estudos sobre incrus-

\footnotetext{
${ }^{11}$ Informações extraidas do curriculo de Dyrce Lacombe. Disponivel em: Acervo da Casa de Oswaldo Cruz, Fundo Dyrce Lacombe. Ref DL-FC-ST-20.

32 Ela foi a nona pesquisadora associada a ingressar na ABC. Naquela época, apenas uma mulher pertencia à categoria titular (MELO, CASEMIRO, 2003).
} 
tação e corrosão causada por esses animais. ${ }^{33}$ Durante esse periodo ela estabeleceu contatos e colaborações com pesquisadores de várias instituições de pesquisa em biologia marinha e entomologia, de que resultaram as publicações em revistas internacionais referidas no Quadro $2 .^{34}$

Quadro 2 - Publicações de Dyrce Lacombe (1955-1970)35

\begin{tabular}{|c|c|c|}
\hline Ano & Autoria & Revista \\
\hline 1955 & Dyrce Lacombe e Rudolf Barth & Memórias do IOC \\
\hline 1956 & Dyrce Lacombe e Rudolf Barth & Memórias do IOC \\
\hline 1957 & Dyrce Lacombe & Memórias do IOC \\
\hline 1958 & Dyrce Lacombe & Studia entomology \\
\hline 1958 & Dyrce Lacombe & Memórias do IOC \\
\hline 1959 & Dyrce Lacombe & Anais Congresso Int. Doença de Chagas \\
\hline 1959 & Dyrce Lacombe e Lauro Travassos & Atas Sociedade Brasileira de Biologia \\
\hline 1960 & Dyrce Lacombe & Boletim do Museu Nacional (Zoologia) \\
\hline 1960 & Dyrce Lacombe & Memórias do IOC \\
\hline 1962 & Dyrce Lacombe & Memórias do IOC \\
\hline 1963 & Dyrce Lacombe & Memórias do IOC \\
\hline 1964 & Dyrce Lacombe & Boletim do Museu Nacional (Zoologia) \\
\hline 1965 & Dyrce Lacombe & Nota técnica Inst. Pesquisas Marinha \\
\hline 1965 & Dyrce Lacombe & Anais Academia Brasileira de Ciências \\
\hline 1966 & Dyrce Lacombe & Nota técnica Inst. Pesquisas Marinha \\
\hline 1967 & Dyrce Lacombe & Nota técnica Inst. Pesquisas Marinha \\
\hline 1968 & Dyrce Lacombe, L. Arvy e T. Shimony & American Zoology \\
\hline 1968 & Dyrce Lacombe, L. Arvy e T. Shimony & American Zoology \\
\hline 1968 & Dyrce Lacombe e L. Arvy & C.R. Acad. Sc. Paris \\
\hline 1969 & Dyrce Lacombe e V.R. Liguori & Abst.Bioch. \\
\hline 1969 & Dyrce Lacombe e V.R. Liguori & Biol. Bull. \\
\hline 1969 & Dyrce Lacombe, L. Arvy e A. Batisse & Ann. Paras. Huaine et Comp. \\
\hline 1970 & Dyrce Lacombe & Biol. Bull. \\
\hline
\end{tabular}

Fonte: Elaborado pelos autores com informações extraídas do currículo de Dyrce Lacombe.

\footnotetext{
Os estudos que ela realizou foram financiados pelo IPqM em parceria com o Osborn Laboratories of Marine Science". Acervo da Casa de Oswaldo Cruz, fundo Dyrce Lacombe. Ref. DL-FC-ST-20.

34 Entre 1967 e 1969, a circulação no ambiente acadêmico norte-americano deu a ela a chance de conquistar uma posição por cinco anos como membro associado da equipe de pesquisa em entomologia do California Academy of Sciences em São Francisco. Ali ela travou conhecimento com Edward S. Ross, destacado entomólogo e curador da coleção entomológica da instituição, que, em sua homenagem, denominou de Archembia Lacombea Ross a um novo gênero da familia Embiidae (insetos) por ele identificado. Acervo da Casa de Oswaldo Cruz, fundo Dyrce Lacombe. Ref. DL-FC-ST-20.

35 Informações extraídas do currículo de Dyrce Lacombe, disponivel em: Acervo da Casa de Oswaldo Cruz, Fundo Dyrce Lacombe. Ref DL-FC-ST-20.
} 
Em seu processo de afastamento do Museu Nacional a zoóloga tentou um pedido de transferência. Ele foi solicitado, em 1962, por Antônio Eugenio Arêa Leão, então substituto do diretor do IOC, ao Ministério da Educação e Cultura, pasta a qual o Museu Nacional estava subordinado. A justificativa destaca que ela trabalhava de forma "voluntária" no IOC desde $1953,{ }^{36}$ realizando estudos em histologia e fisiologia de insetos, "achando-se, pela natureza de seu trabalho, mais intimamente ligada ao tipo de pesquisas aqui realizadas, sobretudo com aquelas que se relacionam com as aplicações no campo da medicina humana e veterinária".37 O ofício assinala ainda que a maioria dos 26 trabalhos publicados por ela até então se relacionava com as pesquisas ali realizadas, "alguns dos quais com enorme cota de sacrificio pessoal, tendo em vista a exiguidade de tempo para atender também as suas obrigações no Museu Nacional".38 Ao final argumenta que ela poderia obter maior rendimento profissional na instituição em vista da ligação que estabelecera durante aqueles anos.

Vale mencionar que essa tentativa para obter a transferência foi concomitante a uma intensa mobilização de 45 bolsistas do IOC, da qual Dyrce era uma das líderes, que reivindicavam a efetivação no quadro de pesquisadores desde que fora aberta essa possibilidade por uma lei federal de 1962.39 Em outubro de 1963, o grupo recebeu um enquadramento provisório no Ministério da Saúde, recebendo a classificação como biologista em caráter definitivo somente em 1969. Ao retornar de uma excursão à Amazônia em 1963, a cientista decidiu se exonerar do Museu Nacional. Ela se aposentou no IOC em 1991, mas permaneceu até os anos 2000 com as pesquisas sobre cracas, embiópteros e histologia de barbeiros, pelas quais foi reconhecida profissionalmente.

\section{Considerações finais}

Em 1957, a Campanha Nacional de Aperfeiçoamento de Pessoal de Nível Superior (CAPES) realizou uma pesquisa com o objetivo de organizar um cadastro nacional das instituições científicas e dos pesquisadores em atividade no pais. Esse inquérito produziu um recenseamento inédito da população de pesquisadores e sua composição por sexo. Foram totalizadas 230 instituições tecno-cientificas (laboratórios, centros de pesquisa, departamentos universitários, entre outros) localizadas em 13 estados da federação e no Distrito Federal, e 3253 pesquisadores, dos quais 2758 homens $(84,8 \%)$ e 495 mulheres $(15,2 \%)$. A maioria das instituições se localizava no Distrito Federal (28,3\%), onde foram identificados 1001 homens $(78,1 \%)$ e 281 mulheres (21,9\%).

A grande diferença quantitativa entre homens e mulheres sobressai nesses dados. Podemos argumentar que o quantitativo menor de mulheres pode ser relacionado à escolarização recente, sobretudo em nivel superior, da qual as faculdades de filosofia, ciências e letras constituiam um marco. Ademais, sabe-se que o diploma de um curso de ciências se direcionava mais para o magistério do que para as funções em uma instituição de pesquisa. Nessa perspectiva podemos indagar: como as mulheres identificadas pelo recenseamento chegaram aquelas posições? Quais atributos foram requeridos para o desempenho das funções que assumiram?

O caso que tratamos aqui fornece indicios que auxiliam a compreensão de pelo menos uma parte do processo de construção de um lugar público pelas mulheres em um campo profissional estritamente masculino até então. A presença de pesquisadoras no Museu Nacional, no Instituto Oswaldo Cruz, e nas demais instituições espalhadas pelo país nos anos 1950, constituiam indubitavelmente uma novidade. A relação entre Dyrce e Newton evidencia a trans-

\footnotetext{
Embora tivesse bolsa desde 1953, ela não possuía um vinculo formal com a instituição.

Ofício dirigido ao Ministério da Educação e Cultura. Acervo da Casa de Oswaldo Cruz, Fundo Dyrce Lacombe. Ref. DL-FC-ST-01. Ibidem.

Essa Lei (4.069 de 11 de junho de 1962, art. 23, parágrafo único) estipulava que: "Os servidores que contem ou venham a contar 5 (cinco) anos de efetivo exercício em atividade de caráter permanente, admitidos até a data da presente Lei, qualquer que seja a forma de admissão ou pagamento, ainda que em regime de convênio ou acordo, serão enquadrados nos termos do art. 19, da Lei n 3.780 , de 12 de julho de 1960". Disponivel em: https://www.planalto.gov.br/ccivil_03/leis/l4069.htm. Acesso em: 23 jul. 2021.
} 
formação dos códigos de sociabilidade no que concerne às relações de gênero, propiciados pela convivência entre homens e mulheres em ambientes de formação intelectual e profissional até então inexistentes. Esse ambiente misto instituido originalmente nas faculdades de filosofia se reproduziu em instituições científicas como o Museu Nacional, em que as práticas de mediação cultural (cursos, estágios, exposições, excursões etc.) possibilitaram a emergência do professor-cientista mediador, representado aqui pelo naturalista Newton Santos. Por meio dessas práticas as jovens licenciadas - no caso de Dyrce uma estudante secundarista - e outras profissionais mulheres, como as professoras, foram recrutadas para as carreiras científicas.

No contexto de valorização e indução dessas práticas de mediação por parte de políticas públicas se articularam ciência, educação e divulgação científicas para a consecução de uma reforma do sistema de educação visando a renovação do ensino de ciências. O Museu Nacional, entre outras instituições, corporificou esse projeto politico-educacional nos anos 1950, que constituia ali, de certa maneira, um legado de gerações anteriores. Ao mesmo tempo, as instituições de pesquisa começaram a oferecer oportunidades para a profissionalização sob o impulso de políticas públicas que forneceram, ainda que inicialmente com muitas restrições, os recursos para a incorporação de estudantes e pesquisadores aos laboratórios. CNPq, CAPES, agências internacionais, como Unesco e Fundação Rockefeller, constituiram exemplos de iniciativas que repercutiram de forma importante em um momento de transição de um padrão de atividade restritivo para um padrão profissional moderno, baseado em oportunidades mais amplas de acesso e na estruturação de uma carreira (SCHWARTZMAN, 2001). A trajetória de Dyrce no Museu Nacional e no IOC é ilustrativa desse processo, e como ele contribuiu para sua incorporação a essas instituições, por meio de cursos, estágio, bolsa e concurso. Esses mecanismos institucionais que passaram a ser implementados, somados às ações dos "mentores", que detinham o poder para acessá-los, geraram as oportunidades que mulheres como Dyrce aproveitaram para viabilizar o projeto profissional que traçaram para si. E, sabemos, ela não foi a única mulher dessas instituições a construir uma trajetória nesses moldes. Nesse sentido, a inserção institucionalizada de mulheres em laboratórios e grupos de pesquisa atuou decisivamente sobre o processo de institucionalização. Não apenas elas promoveram a renovação disciplinar de vários campos de pesquisa, como sua presença gerou tensões nas hierarquias e posições estabelecidas.

\section{Referências}

AZEVEDO, Nara; FERREIRA, Luiz Otávio. Modernização, politicas públicas e sistema de gênero no Brasil: educação e profissionalização feminina entre as décadas de 1920-1940. Cadernos Pagu, Campinas, SP, n. 27, p. 217-254, jul./dez. 2006.

BACKES, Tayza. GAERTNER, Rosinete. Educação e memória: inventário das obras publicadas na área de matemática pela campanha de aperfeiçoamento e difusão do ensino secundário (CADES). Dynamis Revista tecno-cientifica, Granada, Espanha, v. 13, n. 1, p. 21-28, out./dez. 2007.

CAMPANHA Nacional de Aperfeiçoamento de Pessoal de Nivel Superior. Instituições de Pesquisa (básica e aplicada). Série Informação, Distrito Federal, v. 5, 1957.

CORRÊA, Mariza. Dona Heloisa e a pesquisa de campo. Revista de Antropologia, São Paulo, v. 40, n. 1, p. 11-54, 1997.

DUARTE, Regina Horta. A biologia militante: o Museu Nacional, especialização científica, divulgação do conhecimento e práticas políticas no Brasil - 1926-1945. Belo Horizonte: UFMG, 2010.

ESTEVES, B. MASSARANI, L. MOREIRA, I. C. Ciência para Todos e a divulgação científica na imprensa brasileira entre 1948 e 1953. Revista da SBHC, Rio de Janeiro, v. 4, n. 1, p. 62-85, jan./jun. 2006.

FÁVERO, Maria de Lourdes de Albuquerque; PEIXOTO, Maria do Carmo de Lacerda; SILVA, Ana Elisa Gerbasi. Professores estrangeiros na Faculdade Nacional de Filosofia, RJ 1939-1951. Cadernos de Pesquisa, São Paulo, n. 78, p. 59-72, 1991.

FÁVERO, Maria de Lurdes Albuquerque. Universidade do Brasil: das origens à construção. Rio de Janeiro: Editora UFRJ: Comped: INEP, 2000.

GOMES, Angela de Castro. HANSEN, Patricia Santos. Intelectuais mediadores: práticas culturais e ação politica. Rio de Janeiro: Civilização Brasileira, 2016.

LACOMBE, Dyrce. Depoimento. Programa de História Oral. Departamento de Arquivo e Documentação. Casa de Oswaldo Cruz/Fiocruz, Rio de Janeiro 1999. Fita 1, lado A. 
LACOMBE, Dyrce. Depoimento. Programa de História Oral. Departamento de Arquivo e Documentação. Casa de Oswaldo Cruz/Fiocruz, Rio de Janeiro, 2005 Fita 1, lado A

MACHADO, Ângelo Barbosa Monteiro COSTA, Janira Martins Obituary. Newton Dias dos Santos. Odonatologica, Flórida, Estados Unidos, v. 19, n. 3, p. 297-308, 1990.

MELO, Hildete Pereira de; CASEMIRO Maria Carolina Pereira. A Ciência no Feminino: uma análise da Academia Nacional de Medicina e da Academia Brasileira de Ciência. Revista Rio de Janeiro, Rio de Janeiro, n. 11, set./dez. 2003. Periódico sem paginação.

MENDONÇA, Ana Waleska. Anisio Teixeira e a escola nova. In: XAVIER, Maria do Carmo (org.). Manifesto dos pioneiros da educação: um legado educacional em debate. Rio de Janeiro: Editora FGV, 2004. p. 241-255.

MENDONÇA, Ana Waleska. Anisio Teixeira e a universidade de educação. Rio de Janeiro: EDUERJ, 2002. 186 p.

MORAES, Carla W. Newton Dias dos Santos, os manuais "Práticas de Ciências" e visões de professor no contexto do movimento renovador do ensino de Ciências nas décadas de 1950-1970. 2010. Dissertação (Mestrado em Educação) - Universidade Federal Fluminense, Rio de Janeiro, 2010.

OLIVEIRA, Sabrina Soares de. A função educativa da Seção de Extensão Cultural do Museu Nacional na gestão do Educador Paschoal Lemme (1943-1946). 2013. Dissertação (Mestrado em Educação) - Faculdade de Formação de Professores, Universidade do Estado do Rio de Janeiro, Rio de Janeiro, 2013.

PAIM, Antônio. A UDF e a ideia de universidade. Rio de Janeiro: Edições Tempo Brasileiro, 1981.

PINTO, Diana Couto. Campanha de Aperfeiçoamento e Difusão do Ensino Secundário: uma trajetória bem-sucedida? In: MENDONÇA, Ana Waleska; XAVIER, Libânia Nacif. Por uma política de formação do magistério nacional: o Inep/MEC dos anos 1950/1960. Brasilia: Instituto Nacional de Estudos e Pesquisas Educacionais Anisio Teixeira, 2008. p. 145-177.

SANTOS, Newton Dias dos. A formação de um naturalista. Revista do Museu Nacional, Rio de Janeiro, ano II, n. 4, p. 4-7, ago. 1945

SANTOS, Newton Dias dos. Práticas de Ciências. 3. ed. Rio de Janeiro: Gráfica Olimpica Editora LTDA, 1968. (Guia de Ensino Elementar).

SCHATZMAYR, Ortrud Monika Barth Dr. Rudolf Barth. Entomologia y Vectores, Rio de Janeiro, v. 8, n. 1, p. 1-26, jan./fev./mar. 2001

SCHWARTZMAN, Simon. Um espaço para a ciência: a formação da comunidade científica no Brasil. Brasilia: Ministério de Ciência e Tecnologia, Centro de Estudos Estratégicos, 2001.

SILY, Paulo Rogério Marques. Casa de ciência, casa de educação: ações educativas do Museu Nacional (1818-1935). 2012. 399 f. Tese (Doutorado em Educação) - Faculdade de Educação, Universidade do Estado do Rio de Janeiro, Rio de Janeiro, 2012.
SPIGUEL, Juliana; SELLES, Sandra Escovedo. Cândido Firmino de Mello Leitão e o ensino de história natural na década de 1930: um intelectual a serviço da escola. Revista HISTEDBR On-Line, Campinas, SP, v. 13, n. 53, p. 115-132, 2013

TRIGO, Maria Helena. A mulher universitária: códigos de sociabilidade e relações de gênero. In: BRUSCHINI, Cristina; SORJ, Bila. Novos Olhares: mulheres e relações de gênero no Brasil. São Paulo: Fundação Carlos Chagas; Marco Zero, 1994. p. 89-109.

ZARUR, George de Cerqueira Leite. A arena científica Campinas: Editora Autores Associados, 1994.

\section{Daiane Silveira Rossi}

Doutora em História das Ciências pela Fundação Oswaldo Cruz (FIOCRUZ), no Rio de Janeiro, RJ, Brasil. Pós-doutoranda no Programa de Pós-Graduação em História das Ciências e da Saúde (PPGHCS), com bolsa FAPERJ nota 10, no Rio de Janeiro, RJ, Brasil.

\section{Nara Azevedo}

Doutora em Sociologia pelo Instituto Universitário de Pesquisas do Rio de Janeiro (IUPERJ), no Rio de Janeiro, RJ, Brasil. Professora do Programa de Pós-Graduação em História das Ciências e da Saúde (PPGHCS), no Rio de Janeiro, RJ, Brasil.

\section{Luiz Otávio Ferreira}

Doutor em História Social pela Universidade de São Paulo (USP), em São Paulo, SP, Brasil. Professor do Programa de Pós-Graduação em História das Ciências e da Saúde (PPGHCS) e professor associado na Faculdade de Educação da Universidade do Estado do Rio de Janeiro (UERJ), no Rio de Janeiro, RJ, Brasil.

\section{Endereço para correspondência}

Daiane Silveira Rossi/ Nara Azevedo/ Luiz Otávio Ferreira

Casa de Oswaldo Cruz

Av. Brasil, 4365

Prédio Centro de Documentação e História da Saúde Departamento de História e Ciências da Saúde, $3^{\circ}$ andar Manguinhos, 21040-900

Rio de Janeiro, RJ, Brasil

Os textos deste artigo foram revisados pela Poá Comunicação e submetidos para validação do(s) autor(es) antes da publicação. 